\title{
Removal of Acid Yellow 25 from Aqueous Solution by Chitin Prepared from Waste Snow Crab Legs
}

\author{
Chin-Chuan Wei ${ }^{1,2 *}$, Inoka K. Pathiraja ${ }^{1}$, Emily Fabry ${ }^{1}$, Kyle Schafer ${ }^{1}$, \\ Nick Schimp1, Tuo-Ping Hu${ }^{2}$, Lawrence P. Norcio ${ }^{1}$ \\ ${ }^{1}$ Department of Chemistry, Southern Illinois University Edwardsville, Edwardsville, USA \\ ${ }^{2}$ Chemical Department, North University of China, Taiyuan, China \\ Email: *cwei@siue.edu
}

How to cite this paper: Wei, C.-C., Pathiraja, I.K., Fabry, E., Schafer, K., Schimp, N., $\mathrm{Hu}$, T.-P. and Norcio, L.P. (2018) Removal of Acid Yellow 25 from Aqueous Solution by Chitin Prepared from Waste Snow Crab Legs. Journal of Encapsulation and Adsorption Sciences, 8, 139-155.

https://doi.org/10.4236/jeas.2018.83007

Received: May 15, 2018

Accepted: July 22, 2018

Published: July 25, 2018

Copyright $\odot 2018$ by authors and Scientific Research Publishing Inc. This work is licensed under the Creative Commons Attribution International License (CC BY 4.0).

http://creativecommons.org/licenses/by/4.0/

\begin{abstract}
Acid Yellow 25 (AY25) is used in the textile industry for dyeing of natural and synthetic fibers, and is also used as a coloring agent in paints, inks, plastics, and leathers. Effluents from such industries are major sources of water pollution. Hence, it is important to find simple, efficient, and inexpensive ways to remove these dyes from wastewater. Here, we determined the suitability of chitin extracted from waste crab legs as an adsorbent for removing AY25 dye. The adsorption kinetics was modeled using pseudo-first order, pseudo-second order, and intraparticle diffusion equations to determine the rate controlling step. Results showed that the pseudo-second order adsorption mechanism is predominant, and the overall rate of the dye adsorption process is therefore controlled by an adsorption reaction. Adsorption isotherms were analyzed by utilizing the Langmuir, Freundlich, Dubinin-Radushkevich (D-R) and Temkin isotherm models at $23^{\circ} \mathrm{C}$, with data collected by using various initial dye concentrations with different chitin dosages. Our results show the highest correlation with the Langmuir model, consistent with the fact that chitin contains both a monolayer and homogeneous adsorption sites. Based on the D-R model, the adsorption of AY25 dye onto chitin is via chemisorption. Furthermore, we have concluded that the rate constants of both pseudo-second order adsorption and film diffusion are correlated to the initial dye concentrations and chitin dosages. In conclusion, chitin from waste crab legs is a very suitable adsorbent material that is capable of rapidly removing up to $95 \%$ of the initial concentration of AY25 dye at a $\mathrm{pH}$ of 2 and room temperature.
\end{abstract}

\section{Keywords}

Acid Yellow 25, Chitin, Adsorption Kinetics, Adsorption Isotherm 


\section{Introduction}

Dyes are widely used by textile, food, paper, paint, and pharmaceutical industries [1], producing tremendous amounts of wastewater. It has been reported that approximately 280,000 tons of textile dyes are dumped into the marine environment worldwide per year [2]. Textile wastewaters typically contain 10 $200 \mathrm{mg} / \mathrm{L}$ of dyes. These industrial dyes are non-degradable and stable to light and oxidizing reagents. Therefore, the disposal of waste dyes into water streams creates an environmental problem. For example, the presence of dyes in rivers and lakes affects aquatic life directly and humans indirectly by 1) reducing light passage, 2) producing toxic breakdown products that eventually find their way into human food chains, and 3) causing skin allergies, cancer, and eye irritation [3]. Acid Yellow 25 (AY25) (Figure 1) is a commonly used dye in the textile industry for dyeing natural fibers like cotton, wool, and silk as well as synthetic fibers like polyesters, acrylic, and rayon in weak acid solutions ( $\mathrm{pH} 2$ to 6) [4], in which the name "acid" originates from the dyeing process. Acid dyes are mainly mono-azo compounds; but can also include diazo, nitro, 1-amino-anthraquinone, triphenyl methane, and other groups of compounds. They also carry one to three sulfonic groups, making them anionic.

Currently, there are many approaches for the treatment of dye wastes. Chemical methods like coagulation, precipitation, electrochemical destruction, electro-flocculation, irradiation, and oxidation, are used to treat wastewater dyes [5]. However, these methods are expensive and they generate toxic derivatives, such as primary aromatic amines and heavy metals, which persist in the treated wastewater. Using microorganisms for the removal of synthetic dyes is relatively

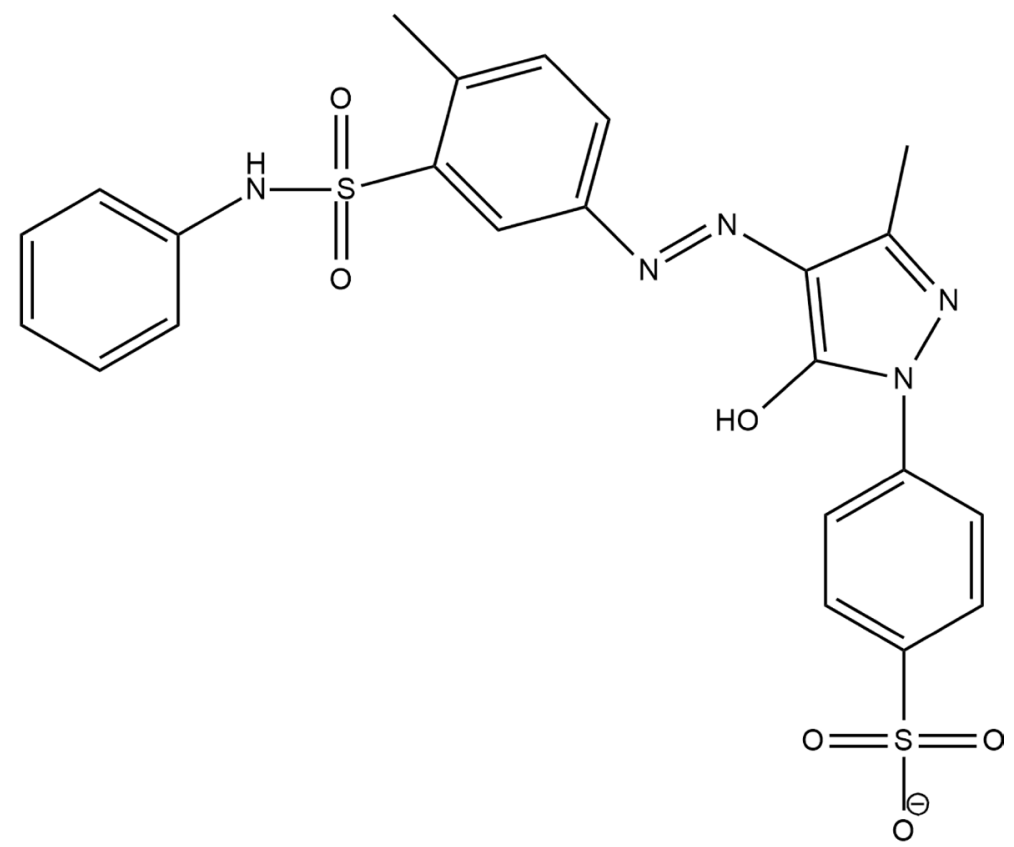

Figure 1. Chemical Structure of Acid Yellow 25 (AY25). 
inexpensive and the breakdown products are completely mineralized. However, the microbiological approach needs a large land area due to the high volume of sludge generated, making this solution a challenge. Furthermore, some of the industrial dyes are resistant to aerobic digestion and thus may not be effectively removed due to their extremely slow oxidation rate [5]. Physical methods like membrane filtration and ion-exchangers have their own drawbacks in dye wastewater removal. For example, filtration membranes have a limited lifetime, are prone to pore clogging, and are costly to replace, while ion-exchangers are not effective for the removal of dyes with a neutral charge [5]. Therefore, biosorption appears to be a better method for the treatment of wastewater. This technology is easily adaptable and the materials used are inexpensive [6]. Various materials like shrimp shells [3] [7], ginger [4], and orange peels [6], have been investigated in the past, but there is still a need to develop cheap and effective biosorbent materials that are specific to dyes with different properties. Here, we used chitin prepared from waste snow crab legs as a sorbent for the removal of AY25 dye from an aqueous solution. The mechanism of adsorption, including the isotherm and kinetics, is reported.

The consumption rate of snow crabs in the United States is nearly 50,000 tons per year [8]. Due to the large consumption rate, waste crab shell management has become another environmental issue. It has been reported that Maryland's Eastern Shore, one of the waste crab shell processing plants in the United States, processes up to 8 million pounds of waste crab shells per year. Thus, using waste crab legs as the raw material for the preparation of chitin, the second most abundant organic resource on the Earth, provides an eco-friendly method that would make use of one waste material to clean up another. Chitin, the major polymer component of the exoskeletons of crustaceans, mollusks, insects and certain fungi, consists of long chain of $\mathrm{N}$-acetyl-D-glucosamine (GlcNAc or 2 -acetamido-2-deoxy-D-glucopyranose) units linked through $\beta$-1,4-glycosidic linkages. Naturally, chitin associates with proteins, organic pigments, and minerals [9].

This crab-waste recycling method will benefit both the food industry and the textile industry by saving on their waste management expenses and their effluent treatment cost, respectively. The objective of this research is to study the suitability of using chitin prepared from waste snow crab legs to remove AY25 dye from aqueous solutions.

\section{Experimental Procedure}

\subsection{Chemicals}

Acid Yellow Dye AY25 (CAS 6353-85-9) was purchased from Sigma-Aldrich (St. Louis, MO) without further purification. Waste snow crab (Chionoecetes opilio) legs were obtained from Dierbergs Market (Edwardsville, IL). All other reagents were purchased from Fisher Scientific. 


\subsection{Chitin Preparation}

The preparation of chitin was carried out as stated in previous reports. Briefly, loose tissues inside the crab legs were scraped out and the shells were washed thoroughly with tap water and finally with deionized water. The shells were dried at room temperature for 2 to 3 days and were ground to a fine powder, followed by demineralization as described previously [10] by using a $0.25 \mathrm{M} \mathrm{HCl}$ solution with a solution to solid ratio of $40 \mathrm{~mL} / \mathrm{g}$ at room temperature. The resulting mixture was filtered through a filter paper (Whatman No. 8). The retained solid powder was washed with deionized water until the filtrate became neutral. Deproteinization was performed using $1.0 \mathrm{M} \mathrm{NaOH}$ at $70^{\circ} \mathrm{C}$ with the ratio of solution to solid of $20 \mathrm{~mL} / \mathrm{g}$ [9]. The deproteinized mixture was then washed with $100 \mathrm{~mL}$ of hot ethanol $\left(60^{\circ} \mathrm{C}\right)$ followed by boiling in $100 \mathrm{~mL}$ acetone for 10 - 15 minutes. The solution was suction filtered and the solid particles were then air dried. The dried chitin was passed through a No. 50 U.S. Standard Sieve followed by a No. 80 Sieve to select particles that were retained on the mesh, with their sizes ranging from 297 to $177 \mu \mathrm{m}$. The purified $\alpha$-chitin was confirmed by the characteristics of the $\mathrm{C}=\mathrm{O}$ stretching at 1655 and $1623 \mathrm{~cm}^{-1}$ and N-H stretching at 3265 and $3100 \mathrm{~cm}^{-1}$ using the Nicolet iS5 FT-IR spectrometer (Thermo Scientific), as well as X-Ray Power Diffractometry (XRD) [10]. The XRD measurements on powdered chitin samples were carried out using a model Rigaku MiniFlex+ X-ray diffractometer equipped with Ni-filtered $\mathrm{Cu} \mathrm{K}_{\beta}$ radiation $(\lambda=1.5406 \AA)$. The relative intensities were recorded between $5^{\circ}-40^{\circ}$ $\left(2 \theta=5^{\circ}-40^{\circ}\right)$ at room temperature. The X-ray diffractometer was operated with $1^{\circ}$ diverging and receiving slits at $50 \mathrm{kV}$ and $40 \mathrm{~mA}$ and a continuous scan was carried out with a step size of $0.015^{\circ}$ and a step time of 0.2 seconds. Peaks were compared with the $\alpha$-chitin peaks obtained from the MDI JADE data base. Five reflections at angles of $9.3^{\circ}, 19.3^{\circ}, 23^{\circ}, 26^{\circ}$, and $36.6^{\circ}$ were detected.

\subsection{AY25 Dye Adsorption by Chitin}

The effects of chitin dosage, $\mathrm{pH}$, and temperature were determined using batch experiments, in which the different amounts of chitin were placed in Erlenmeyer flasks containing different dye concentrations at varying $\mathrm{pH}$ and temperatures. A calibration curve of absorbance at $392 \mathrm{~nm}$ versus the known concentration of AY25 was obtained in order to determine the dye concentration that remained in the solutions for the characterization below. The total volume for each flask was $25 \mathrm{~mL}$ and the flasks were placed on a water-bath shaker (New Brunskwick Scientific, Edison NJ) at $70 \mathrm{rpm}$. Approximately $1 \mathrm{~mL}$ of dye solution from each flask was removed at different time intervals for 150 minutes. The samples were centrifuged at 13,000 rpm for 1 minute using a Brinkmann 5412 centrifuge. The absorbance values of the resulting supernatants after dilution were measured at $392 \mathrm{~nm}$ using a UV-1800 double-beam spectrometer (Shimadzu, Kyoto, Japan). The dye concentrations remaining in each solution (after correction for dilution factor if necessary) were determined. The dye removal efficiency $(E \%)$ was cal- 
culated as:

$$
E \%=\frac{C_{i}-C_{f}}{C_{i}} \times 100 \% \text { or } \frac{A_{i}-A_{f}}{A_{i}} \times 100 \%
$$

where $C_{i}$ (or $A_{i}$ ) and $C_{f}$ (or $A_{f}$ ) are the initial and final concentrations in $\mathrm{mg} / \mathrm{L}$ (or absorbance at $392 \mathrm{~nm}$ ) of AY25 in liquid, respectively. The adsorption capacity at time $t$ ( $q_{t}$ in unit of $\mathrm{mg} / \mathrm{g}$ ) was determined by Equation (2).

$$
q_{t}=\frac{\left(C_{o}-C_{t}\right) V}{m}
$$

where $C_{o}$ and $C_{t}$ are the initial dye concentration and the concentration at time $t$ in the liquid phase $(\mathrm{mg} / \mathrm{L})$, respectively, $m$ is the mass of chitin $(\mathrm{g})$, and $V$ is the volume of the aqueous phase $(\mathrm{L})$. Adsorptive capacity at equilibrium $\left(q_{e}\right)$ is a measurement of how well a certain adsorbent adsorbs the adsorbate in solution. This term is utilized for a better comparison and is important to judge the performance of an adsorbent. The value of $q_{e}$ can be calculated by the equation below.

$$
\text { Adsorptive Capacity }\left(q_{e}\right)=\frac{\text { Amount of dye adsorbed }(\mathrm{mg})}{\text { Amount of Chitin }(\mathrm{g})}
$$

The data presented in the results section are reproducible and are from at least four separated trials using at least two different batches of chitin.

\section{Results and Discussion}

\subsection{The pH, Temperature, and Dosage Effect of AY25 Dye Adsorption to Chitin}

We isolated chitin from waste crab legs by the demineralization and deproteinization processes as described previously [10]. The IR spectrum and X-ray diffraction data (data not shown) of the resulting purified chitin indicate that the $\alpha$ form of chitin was obtained, which was consistent with a previous report [10]. To determine the optimal $\mathrm{pH}$ for the AY25 adsorption by chitin, the measurements were conducted in a solution containing $58 \mathrm{mg} / \mathrm{L} \mathrm{AY25}$ and $3 \mathrm{~g} / \mathrm{L}$ of chitin (particle size of 297 to $177 \mu \mathrm{m}$ ) at $\mathrm{pH}$ values ranging from 1 to 12 at room temperature (Figure 2(a)). The dye concentration in the liquid phase was determined after $0.5,1$, and 2 hour incubation periods. Our results show that the dye adsorption increased over time (data not shown). The dye removal efficiency was more than $50 \%$ for $\mathrm{pH}$ values ranging from 2 to 7 with the highest adsorption at $\mathrm{pH}$ 2. A pH higher than 8 resulted in less than $30 \%$ of dye removal. These observations suggest that the positively charged chitin, resulting from the protonation of the amino group of chitin under acidic conditions [11], interacts with the negatively charged sulfonic group of the dye. Such ionic interactions are diminished at $\mathrm{pH} 1$, possibly due to the conversion of the sulfonic salt to sulfonic acid in very acidic conditions. AY25 is considered to be a strong acid due to its sulfonic group with a low $\mathrm{pK}_{\mathrm{a}}$, as seen in P-toluenesulfonic acid with its $\mathrm{pK}_{\mathrm{a}}=$ -2.1 . Similarly, the solutions with a higher $\mathrm{pH}$ resulted in less protonation of the 


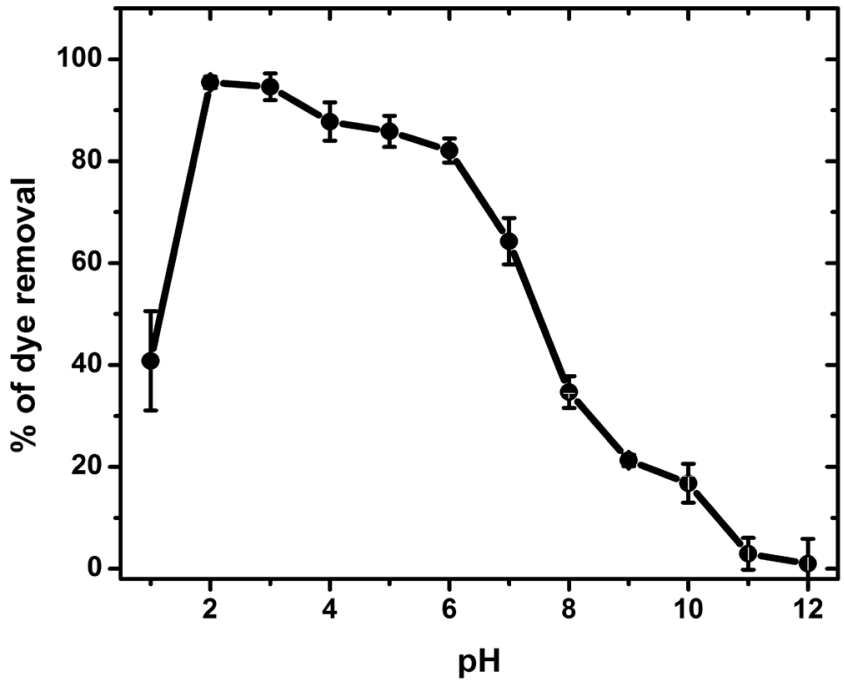

(a)

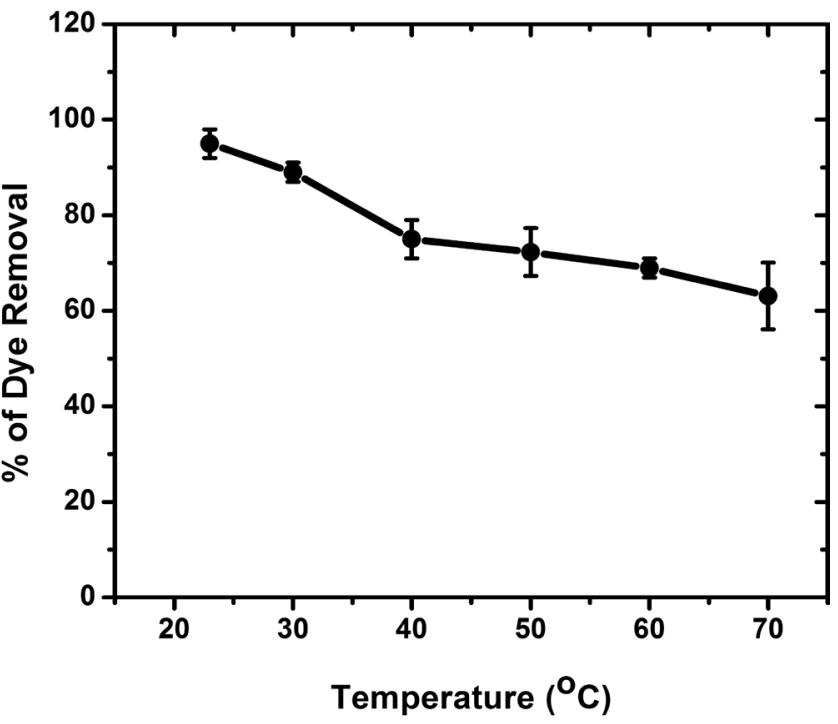

(b)

Figure 2. The Effects of $\mathrm{pH}$ and Temperature. The initial dye and total chitin concentrations were $385 \mathrm{mg} / \mathrm{L}$ and $3 \mathrm{~g} / \mathrm{L}$, which were incubated in the different $\mathrm{pH}$ solutions (a) or at specific temperatures (b) at a speed of $70 \mathrm{rpm}$.

amino group in chitin that weakens the ionic interaction as well. We also determined the effect of temperature on dye adsorption by chitin by utilizing $58 \mathrm{mg} / \mathrm{L}$ AY25 with $3 \mathrm{~g} / \mathrm{L}$ chitin at $\mathrm{pH} 2$ and $70 \mathrm{rpm}$. Our results revealed that higher temperatures have a lower efficiency of dye removal (Figure 2(b)), and the efficiency at room temperature $\left(23^{\circ} \mathrm{C}\right)$ appears to be optimal for dye removal.

We then determined the dosage effect of chitin at $23^{\circ} \mathrm{C}$. At a low initial dye concentration $(58 \mathrm{mg} / \mathrm{L})$, the adsorption of dye onto chitin is very effective and reaches equilibrium quickly. For example, the dye removal reaches $90 \%$ within 15 min of contact time with the exception of the chitin dosage of $1 \mathrm{~g} / \mathrm{L}$, which reaches equilibrium in $\sim 1 \mathrm{hr}$ (Figure 3(a)). Following the maximum adsorption, the system reaches a state of dynamic equilibrium between dye being adsorbed onto and desorbed from chitin. When the initial dye concentration was increased, more chitin was required (Figure $3(\mathrm{~b})$ ). When the initial dye concentration was $385 \mathrm{mg} / \mathrm{L}$, at least $3 \mathrm{~g} / \mathrm{L}$ of chitin was required to remove $90 \%$ of the dye within $1 \mathrm{hr}$. This observation was expected, as the increase in adsorption with higher adsorbent dosage is attributed to an increased adsorbent surface and the availability of more adsorption sites. Thus we chose the chitin dosages of 3,4 , and $5 \mathrm{~g} / \mathrm{L}$ and initial dye concentrations of $58,165,284$, and $385 \mathrm{mg} / \mathrm{L}$ for our adsorption kinetics and isotherm studies.

\subsection{Adsorption Kinetics}

Adsorption kinetics provides information about the interactions between the adsorbent and adsorbate, which are important to understand the adsorption process conditions. Typically, dye adsorption kinetics is influenced by the adsorption and mass transfer steps, including external- and intra-particle diffusions that are related to the structure of the absorbent (e.g. particle size and 


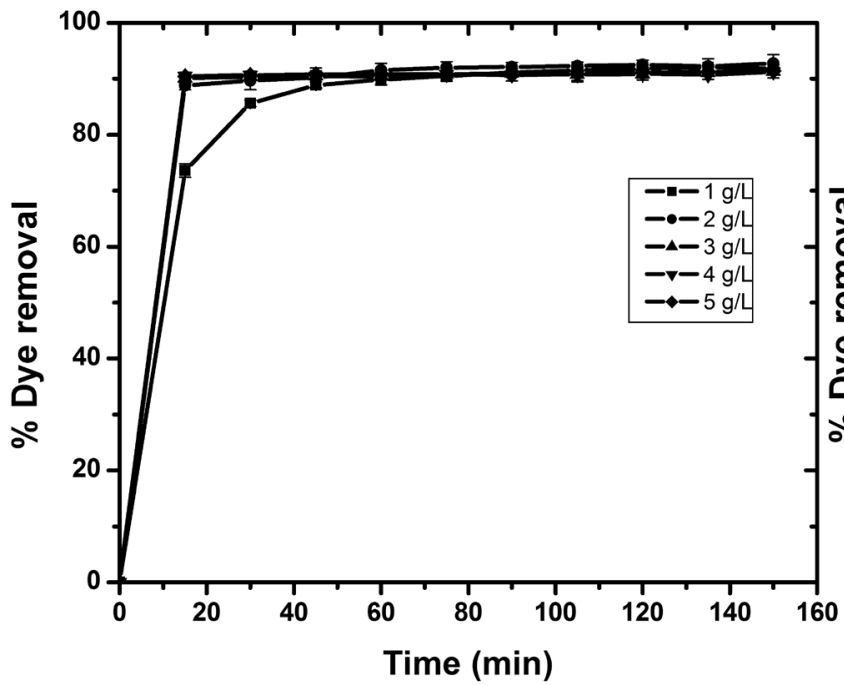

(a)

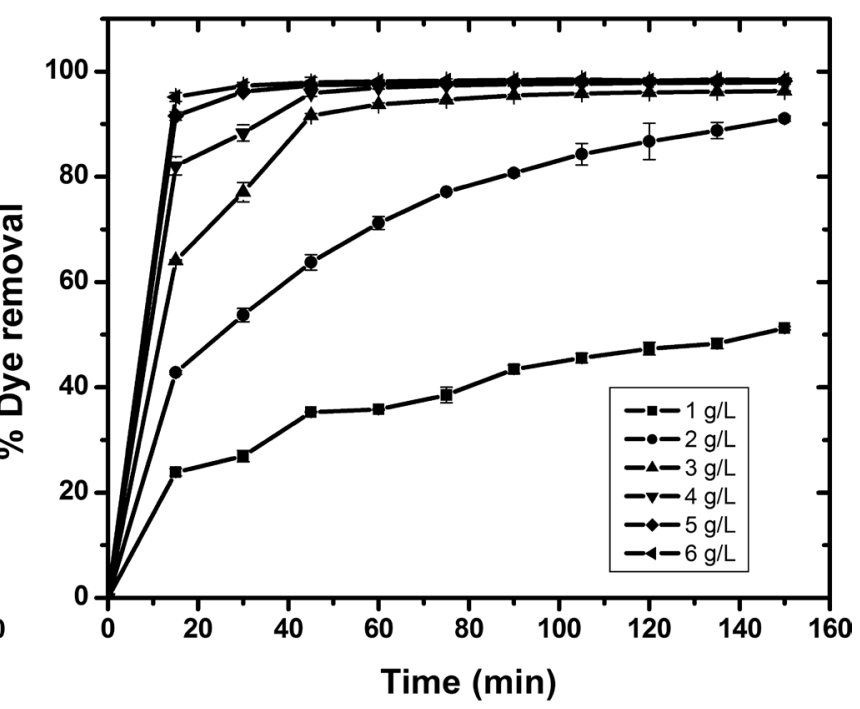

(b)

Figure 3. Effect of Initial Dye Concentration on Adsorptive Capacity. The batch experiments were conducted at $23^{\circ} \mathrm{C}$ and $\mathrm{pH}=2$ using $58 \mathrm{mg} / \mathrm{L}$ (a) and $385 \mathrm{mg} / \mathrm{L}$ (b) of AY25.

intrinsic property), the nature of adsorbate, and the process conditions such as temperature, $\mathrm{pH}$, and mixing speed. Many models, including pseudo-first order, pseudo-second order, and intra-particle diffusion models, have been employed to describe the kinetic processes.

The pseudo-first order kinetic model is expressed as:

$$
\log \left(q_{e}-q_{t}\right)=\log q_{e}-\frac{k_{1}}{2.303} t
$$

where $q_{e}$ is the amount of dye adsorbed at equilibrium $(\mathrm{mg} / \mathrm{g}), q_{t}$ is the amount of dye adsorbed at time $t$, and $k_{1}$ is the equilibrium rate constant for pseudo-first order kinetics $\left(\mathrm{min}^{-1}\right)$. The pseudo-first order model is based on the rate of adsorption being related to the concentration difference of adsorbate between the solution and the surface of adsorbent. In such a process, the adsorption process is primarily controlled by the external mass transfer coefficient. For this model, a linear plot of $\log \left(q_{e}-q_{t}\right)$ versus $t$ (Equation (4)) is anticipated and the resulting slope corresponds to the value of $k_{1}$. However, the pseudo-first order equation cannot be applied well for a slow adsorption process and, therefore, is generally limited for the adsorption with a short contact time [12]. The adsorption of AY25 onto chitin cannot be described by the pseudo-first order model (data not shown) as its application at different initial dye concentrations $\left(58,165,284\right.$, and $385 \mathrm{mg} / \mathrm{L}$ ) resulted in very low $R^{2}$ values (Table 1 ).

We then fit our data with a pseudo-second order model, which includes the same equation for both internal and external mass transfer mechanisms as expressed by the following formula:

$$
\frac{t}{q_{t}}=\frac{1}{k_{2} q_{e}^{2}}+\left(\frac{1}{q_{e}}\right) t
$$


where $k_{2}$ is the pseudo-second order rate constant $\left(\mathrm{g} \cdot \mathrm{mg}^{-1} \cdot \mathrm{min}^{-1}\right)$. An example showing a linear fit of $t / q_{t}$ versus contact time ( $\mathrm{t}$ ) for $165 \mathrm{mg} / \mathrm{L}$ initial dye concentration with 3, 4, and $5 \mathrm{~g} / \mathrm{L}$ of chitin is shown in Figure 4(a), and the fitting results for other initial dye concentrations are listed in Table 1. The fitting with $R^{2}>0.9993$ yields the pseudo-second order rate constant $k_{2}$ and the calculated $q_{e}$ $\left(q_{e, c a l}\right)$ agrees with the experimental ones $\left(q_{e, \text { exp }}\right)$ derived from the experiments

Table 1. Kinetic parameters for AY25 dye adsorption onto chitin at different initial dye concentrations and different adsorbent dosages at $23^{\circ} \mathrm{C}$ and $\mathrm{pH}=2$.

\begin{tabular}{cccccccc}
\hline & & \multicolumn{3}{c}{ Pseudo-first order } & \multicolumn{3}{c}{ Pseudo-second order } \\
\cline { 3 - 8 } $\begin{array}{c}\text { Initial } \\
\text { Conc. }(\mathrm{mg} / \mathrm{L})\end{array}$ & $\begin{array}{c}\boldsymbol{q}_{e, \text { exp }} \\
(\mathrm{mg} / \mathrm{g})\end{array}$ & $\begin{array}{c}\boldsymbol{q}_{e, c a l} \\
(\mathrm{mg} / \mathrm{g})\end{array}$ & $\begin{array}{c}\boldsymbol{k}_{1} \\
\left(\mathrm{~min}^{-1}\right)\end{array}$ & $R^{2}$ & $\begin{array}{c}\boldsymbol{q}_{e, c a l} \\
(\mathrm{mg} / \mathrm{g})\end{array}$ & $\begin{array}{c}k_{2} \\
\left(\mathrm{~g} \cdot \mathrm{mg}^{-1} \cdot \mathrm{min}^{-1}\right)\end{array}$ & $R^{2}$ \\
\hline $58^{\mathrm{a}}$ & 17.73 & 0.097 & 0.002 & 0.0427 & 17.67 & 0.3027 & 0.9999 \\
$58^{\mathrm{b}}$ & 13.54 & 0.124 & 0.008 & 0.7734 & 13.49 & 0.4210 & 0.9999 \\
$58^{\mathrm{c}}$ & 10.85 & 0.163 & 0.016 & 0.7404 & 10.82 & 0.6668 & 0.9999 \\
$165^{\mathrm{a}}$ & 53.88 & 1.16 & 0.031 & 0.8454 & 54.35 & 0.0385 & 1.0000 \\
$165^{\mathrm{b}}$ & 35.87 & 0.434 & 0.014 & 0.5338 & 35.97 & 0.1137 & 1.0000 \\
$165^{\mathrm{c}}$ & 28.82 & 0.113 & 0.008 & 0.6067 & 28.82 & 0.5016 & 1.0000 \\
$284^{\mathrm{a}}$ & 92.07 & 17.29 & 0.040 & 0.9437 & 92.94 & 0.0070 & 0.9999 \\
$284^{\mathrm{b}}$ & 69.32 & 2.354 & 0.027 & 0.8829 & 69.64 & 0.0277 & 1.0000 \\
$284^{\mathrm{c}}$ & 55.58 & 0.719 & 0.013 & 0.5887 & 55.56 & 0.0562 & 0.9999 \\
$385^{\mathrm{a}}$ & 127.17 & 65.90 & 0.045 & 0.9818 & 130.72 & 0.0021 & 0.9993 \\
$385^{\mathrm{b}}$ & 98.08 & 25.55 & 0.047 & 0.9656 & 99.90 & 0.0049 & 0.9997 \\
$385^{\mathrm{c}}$ & 78.64 & 4.61 & 0.032 & 0.8775 & 79.18 & 0.0137 & 0.9999 \\
\hline
\end{tabular}

a,b,c, The concentrations of chitin are $3,4,5 \mathrm{~g} / \mathrm{L}$, respectively.

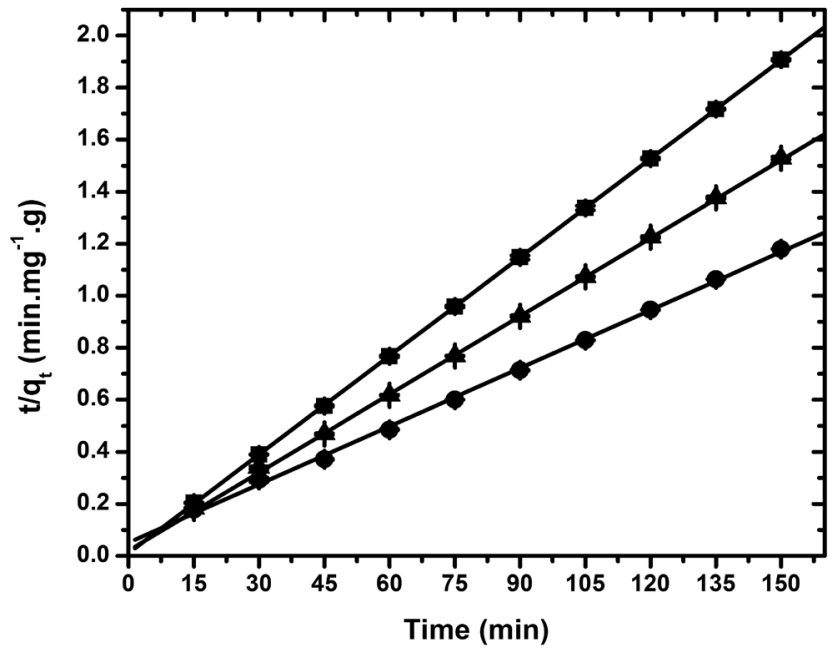

(a)

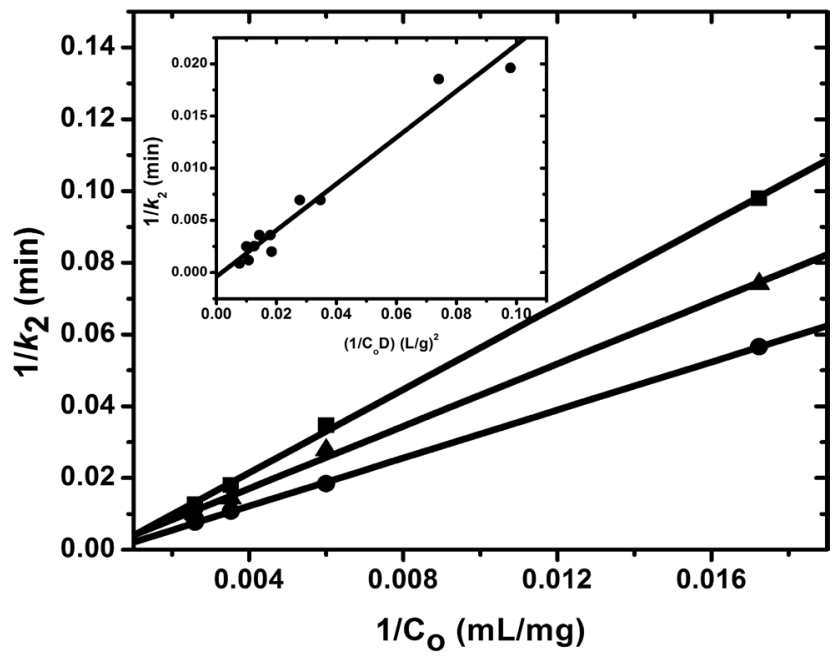

(b)

Figure 4. Adsorption Kinetics of AY25 onto Chitin. The pseudo-second order kinetics were conducted using $385 \mathrm{mg} / \mathrm{L}$ AY25 in the presence of 3 (circle), 4 (triangle), and 5 (square) $\mathrm{g} / \mathrm{L}$ of chitin at $\mathrm{pH} 2$ and $23^{\circ} \mathrm{C}(\mathrm{a})$. The plots of $1 / k_{2}$ versus $1 / C_{o}(\mathrm{~b})$ and $C_{o} D$ (Insert) were analyzed using Equation (6) and Equation (7), respectively. 
conducted shown in Figure 2. The results indicate the pseudo-second order model is adequate for describing the AY25/chitin adsorption process. The pseudo second-order model is consistent with a previous study showing that a higher $k_{2}$ is associated with a lower initial dye concentration for a fixed chitin dosage (see Table 1). It has been shown that $k_{2}$ is a complex function of initial concentration $C_{o}$ [13], and their relationship can be expressed as the following based on the theoretical derivation by Aziaian [14].

$$
\begin{gathered}
k_{2}=C_{o}\left(A_{k} C_{o}+B_{k}\right) \text { and } \\
1 / k_{2}=A_{k}+B_{k}\left(1 / C_{o}\right)
\end{gathered}
$$

where $A_{k}\left(\mathrm{mg} \cdot \mathrm{min} \cdot \mathrm{g}^{-1}\right)$ and $B_{k}\left(\mathrm{mg}^{2} \cdot \mathrm{min} \cdot \mathrm{g}^{-1} \cdot \mathrm{L}^{-1}\right)$ are fitting constants, and can be determined by the plot of $1 / k_{2}$ versus $1 / C_{o}$. Our data shows the linearity for each plot at different chitin dosages (Figure $4(\mathrm{~b})$ ) with the $B_{k}$ values of $3.346,4.342$, and $5.816 \mathrm{mg}^{2} \cdot \mathrm{min} \cdot \mathrm{g}^{-1} \cdot \mathrm{L}^{-1}$ for 3,4 , and $5 \mathrm{~g} / \mathrm{L}$ chitin, respectively. The values of $B_{k}$ increase with the increase of dosage, indicating that $k_{2}$ is also dependent on chitin dosage. Interestingly, our data can be fit well when considering the amount of adsorbent into Equation (6), as shown in the following.

$$
1 / k_{2}=A_{k}+B_{k}^{\prime}\left(1 / C_{o} D\right)
$$

where $D$ is the amount of chitin in $\mathrm{g} / \mathrm{L}$ and $B_{k}^{\prime} \quad\left(\mathrm{mg}^{2} \cdot \mathrm{min} \cdot \mathrm{L}^{-2}\right)$ is the new fitting parameter. The values of $A_{k}$ and $B_{k}^{\prime}$ obtained by the fitting with Equation (7) are $0 \mathrm{mg} \cdot \mathrm{min} \cdot \mathrm{g}^{-1}$ and $0.222 \mathrm{mg}^{2} \cdot \mathrm{min} \cdot \mathrm{L}^{-2}$, respectively, with $R^{2}=0.9824$ (the insert in Figure 4(b)).

Our observations suggest an intra-particle diffusion that may be involved in this sorption phase. The possibility can be explored by plotting $q_{t}$ versus $t^{1 / 2}$ (i.e. W-M plot) based on the Weber and Morris model [15]. Such intraparticle diffusion can be determined from the initial adsorption process via the following equation.

$$
q_{t}=k t^{1 / 2}+C
$$

where $k$ is the intra particle diffusion rate constant $\left(\mathrm{mg} \cdot \mathrm{g}^{-1} \cdot \mathrm{min}^{1 / 2}\right)$. While $k$ provides information for the diffusion process, the value of $C$ carries profound information, such as the thickness of the boundary layer that controls the process. For $C=0$ (i.e. the fitting line passes through the origin), the intraparticle diffusion is the rate controlling step. Multilinearity of W-M plots has been reported. Typically for adsorption, the first linear sorption process involves the fastest dye migration to external surfaces of chitin via either external surface adsorption or boundary layer diffusion. The second linear adsorption phase is attributed to a slower intra-particle diffusion followed by a third linear final equilibrium stage, in which the diffusion is very slow due to very low dye concentration left in the solution. We only observed two linear portions of the adsorption in our case. The adsorption process is very rapid such that the adsorption kinetics cannot be determined precisely during the onset of the adsorption. Figure 5 shows the plot of $q_{t}$ versus $t^{1 / 2}$ for $385 \mathrm{mg} / \mathrm{mL}$ dye and 3, 4, and $5 \mathrm{~g} / \mathrm{L}$ chitin, in which the first 


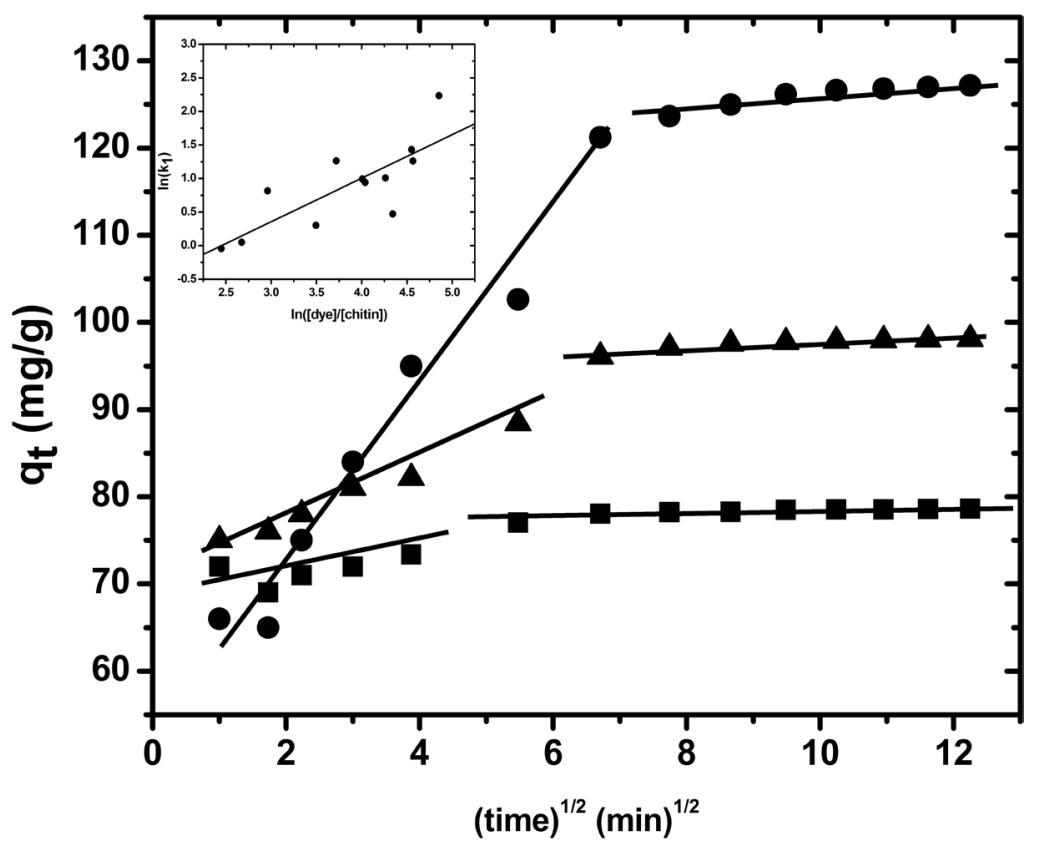

Figure 5. Weber-Morris Plot of AY25 Adsorption onto Chitin and the Correlation to the Amounts of AY25 and Chitin. The experiments were conducted using $385 \mathrm{mg} / \mathrm{L}$ AY25 in the presence of 3 (circle), 4 (triangle), and 5 (square) g/L of chitin at $\mathrm{pH} 2$ and $23^{\circ} \mathrm{C}$. Two linear portions of the adsorption were fitted with the $\mathrm{W}-\mathrm{M}$ equation and the rate constants are summarized in Table 2. The insert shows the correlation between $\ln k_{1}$ and $\ln ([\mathrm{AY} 25] /[$ chitin] $)$.

linear region corresponds to the boundary layer diffusion with the $k_{1}$ values of $9.3235,3.5211$, and $1.4478 \mathrm{~min}^{-1}$. The second linear portions can be explained by the intraparticle diffusion, a slow process giving $k_{2}$ values of $0.3457,0.1582$, and $0.0972 \mathrm{mg} \cdot \mathrm{g}^{-1} \cdot \mathrm{min}^{1 / 2}$ (Table 2). The lines do not pass through the origin, indicating that intraparticle diffusion is only a part of the rate determining step while the boundary layer diffusion controls the adsorption to some degree. The assignments for the individual adsorption processes are reasonable given that chitin's structure is typically rigid and nonporous which renders a slower intraparticle diffusion [1]. Similarly, we performed the dye adsorption using lower initial concentrations of dye against 3,4 , and $5 \mathrm{~g} / \mathrm{L}$ of chitin. The results were consistent with the previous observation, indicating both the boundary layer and intraparticle diffusion rates are inversely proportional to the dosages of chitin. Interestingly, Cheung et al. [15] studied the adsorption of several acid dyes onto chitosan and showed that $k_{1}$ (the uptake process) is more significantly affected by the initial concentration $\left(C_{o}\right)$, but not by the mass of chitosan. They obtained straight lines from the plot of $\ln k_{1}$ versus $\ln C_{o}$ and demonstrated that the first phase of adsorption can be fitted by:

$$
k_{1}=A_{n} C_{o}^{B_{n}}
$$

where $A_{n}$ and $B_{n}$ are the fitting parameters. However, our study showed that the first phase of the adsorption of AY25 onto chitin is also affected by the amount of adsorbent (D). The plot of $\ln \left(k_{1}\right)$ versus $\ln ([$ dye]/[chitin] $]$ in our study suggests 
Table 2. Film and Intra-particle diffusions for AY25 dye adsorption onto chitin at different initial dye concentrations and different adsorbent dosages at $23^{\circ} \mathrm{C}$ and $\mathrm{pH}=2$.

\begin{tabular}{ccccc}
\hline $\begin{array}{c}\text { Initial Conc. }(\mathrm{mg} / \mathrm{L}) \\
(\text { dye/chitin: } \mathrm{mg} / \mathrm{g})\end{array}$ & \multicolumn{3}{c}{ Film and Intra-particle diffusion models } \\
\cline { 2 - 5 } & $\begin{array}{c}\boldsymbol{k}_{1} \\
\left(\mathrm{mg}^{-1} \cdot \mathrm{min}^{1 / 2}\right)\end{array}$ & $\boldsymbol{R}^{2}$ & $\begin{array}{c}\boldsymbol{k}_{2} \\
\left(\mathrm{mg} \cdot \mathrm{g}^{-1} \cdot \mathrm{min}^{1 / 2}\right)\end{array}$ & $\boldsymbol{R}^{2}$ \\
\hline $58(19.33)^{\mathrm{a}}$ & 2.2595 & 0.9798 & 0.0253 & 0.8761 \\
$58(14.50)^{\mathrm{b}}$ & 1.0496 & 0.5875 & 0.001 & 0.5875 \\
$58(11.60)^{\mathrm{c}}$ & 0.9553 & 0.8717 & 0.011 & 0.7828 \\
$165(55.00)^{\mathrm{a}}$ & 2.6921 & 0.7421 & 0.1855 & 0.9827 \\
$165(41.25)^{\mathrm{b}}$ & 3.5274 & 0.9617 & 0.0461 & 0.7548 \\
$165(33.00)^{\mathrm{c}}$ & 1.352 & 0.7226 & 0.017 & 0.9663 \\
$284(94.67)^{\mathrm{a}}$ & 4.1732 & 0.8276 & 0.1719 & 0.9397 \\
$284(71.00)^{\mathrm{b}}$ & 2.7384 & 0.9189 & 0.0991 & 0.9799 \\
$284(56.80)^{\mathrm{c}}$ & 2.5635 & 0.9614 & 0.0704 & 0.8624 \\
$385(128.33)^{\mathrm{a}}$ & 9.3235 & 0.9749 & 0.3457 & 0.9628 \\
$385(96.25)^{\mathrm{b}}$ & 3.5211 & 0.9795 & 0.1583 & 0.9669 \\
$385(77.00)^{\mathrm{c}}$ & 1.4478 & 0.8432 & 0.0972 & 0.8584 \\
\hline
\end{tabular}

a,b,c, The concentrations of chitin are $3,4,5 \mathrm{~g} / \mathrm{L}$, respectively.

a correlation among the film diffusion rate, the dye and chitin concentrations. Thus, Equation (9) can be modified as:

$$
k_{1}=A_{n}\left(\frac{C_{0}}{D}\right)^{B_{n}}
$$

Note that the poor fitting $\left(R^{2}=0.7945\right)$ is mainly due to the experimental errors associated with the measurements for the rapid adsorption of this phase. Though the basis of the correlation is not known, our results indicate that the mass transfer process of AY25 adsorption onto the chitin surface from the onset of the process is very quick, followed by a slower intraparticle diffusion, and both processes are controlled by the "availability" of dye to the surface of chitin.

\subsection{Adsorption Isotherms}

Adsorption isotherms can be used to explain the adsorption in equilibrium at a specific temperature, which provides a better understanding of the surface properties of the adsorbent and the adsorption behavior. Thus we analyzed our data using several established adsorption isotherm models, including Langmuir, Freundlich, and Dubinin-Radushkevich (D-R). To do so, we studied the effect of chitin dosage on equilibrium dye concentration $\left(C_{e q}\right)$ by using an initial dye concentration of $385 \mathrm{mg} / \mathrm{L}$ and chitin dosages from 1 to $5 \mathrm{~g} / \mathrm{L}$, shown in Figure 6. First, we obtained isotherm parameters using the Langmuir adsorption model, which assumes that 1) the surface contains a homogeneous monolayer and 2) the adsorption sites are identical and independent [16]. The Langmuir equation 

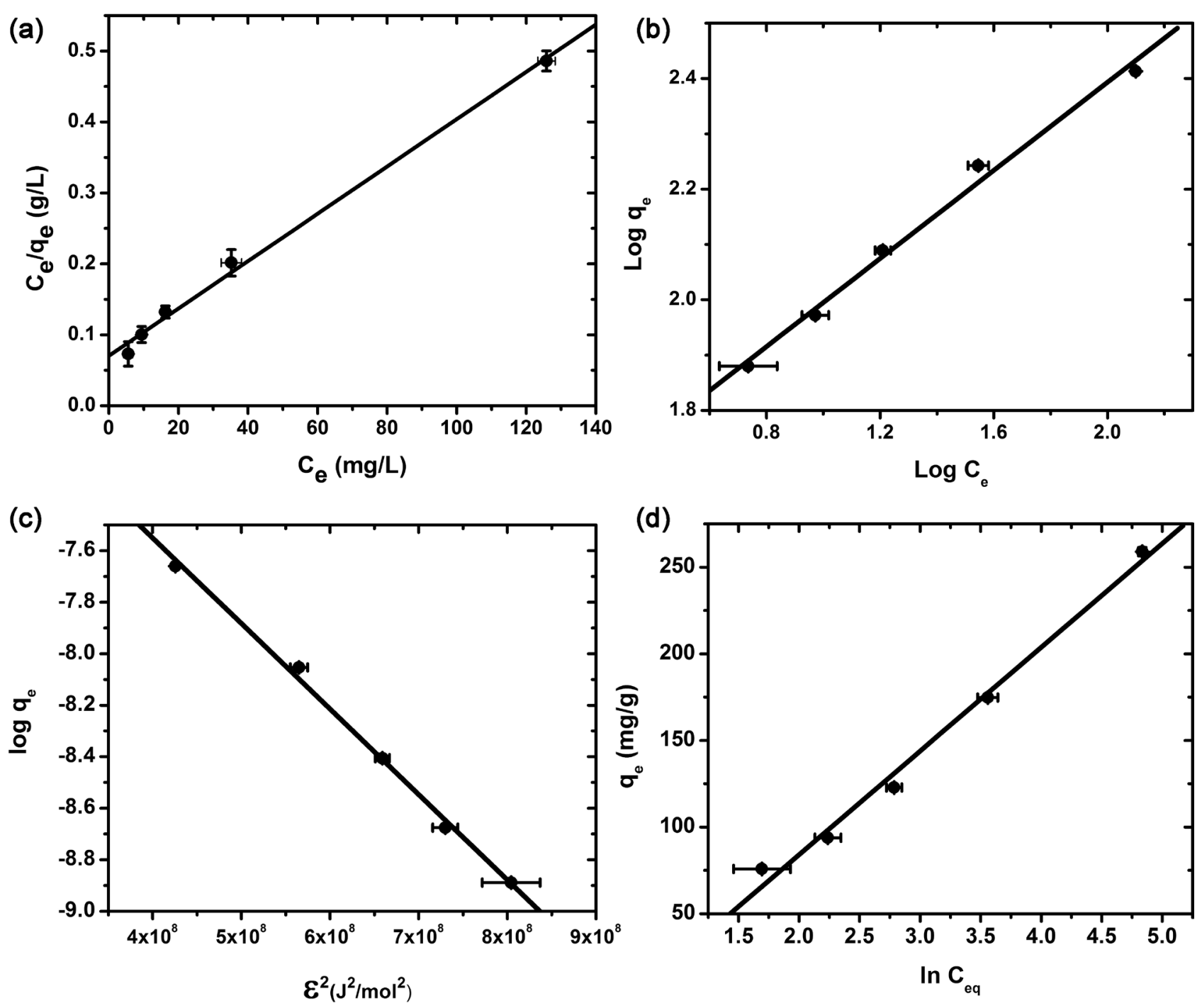

Figure 6. Isotherm Parameters Obtained from Different Models. The experiments were conducted with the initial dye concentration of $385 \mathrm{mg} / \mathrm{L}$ and chitin dosages of $1,2,3,4$, and $5 \mathrm{~g} / \mathrm{L}$ at $23^{\circ} \mathrm{C}$ and $\mathrm{pH}=2$. Four different isotherm models were used for analysis: Langmuir (a), Freundlich (b), D-R (c), and Temkin (d). The parameters obtained from fitting were summarized in Table 3.

is shown in the following.

$$
\frac{q_{e}}{q_{\max }}=\frac{b C_{e}}{1+b C_{e}}
$$

where $q_{e}$ and $q_{\max }$ are the equilibrium concentration of adsorbate adsorbed per adsorbent $(\mathrm{mg} / \mathrm{g})$ and saturation capacity of adsorbent $(\mathrm{mg} / \mathrm{g})$ forming the monolayer, respectively; $C_{e}$ is equilibrium concentration of the adsorbate $(\mathrm{mg} / \mathrm{L})$ and $b$ is the Langmuir adsorption constant $(\mathrm{L} / \mathrm{mg})$ that is related to the heat of adsorption. The essential characteristic of the Langmuir isotherm can be expressed by the dimensionless constant called the equilibrium parameter (separation factor), $R_{L}$, as defined below.

$$
R_{L}=\frac{1}{1+b C_{o}}
$$


where $C_{o}$ is the initial dye concentration $(\mathrm{mg} / \mathrm{L})$.

Our results reveal that the dye adsorption process fits the Langmuir adsorption model well (Table 3), indicating that the adsorption process takes place at the binding sites of chitin near the monolayer of the chitin surface, in which there is no further adsorption at that particular site when that site is occupied by a dye molecule. $R_{L}$ values indicate the type of isotherm to be irreversible $\left(R_{L}=0\right)$, favorable $\left(0<R_{L}<1\right)$, linearly adsorptive $\left(R_{L}=1\right)$, or unfavorable $\left(R_{L}>1\right)$ [17]. The $R_{L}$ value for the adsorption of AY25 dye onto chitin is 0.045 (Table 3), which indicates that the adsorption is favorable. The behavior is consistent with the Type I Langmuir isotherm, suggesting a unimolecular adsorption that applies to microporous adsorbents with small pore sizes.

In contrast to the Langmuir isotherm, the empirical Freundlich isotherm is used to describe the adsorption onto a heterogeneous surface or surfaces containing binding sites with different binding affinities. In this model, the strong binding site is occupied first followed by a weaker binding. The Freundlich isotherm is given by Equation (12) [16].

$$
\begin{gathered}
q_{e}=K_{F} C_{e q}^{1 / n} \\
\log q_{e}=\frac{1}{n} \log C_{e q}+\log K_{F}
\end{gathered}
$$

where $K_{F}$ and $n$ are the Freundlich constant and heterogeneity factor (or adsorption intensity), and $C_{e q}$ is the concentration of adsorbate remaining in solution. The $1 / n$ values indicate the type of isotherm to be irreversible $(1 / n=0)$, favorable $(0<1 / n<1)$, or unfavorable $(1 / n>1)$. If $n=1$ then the partition between the two phases are independent of the concentration. The calculated $R^{2}$ value $(R=$ 0.9884 ) indicates that the equilibrium data in this study fairly agrees with the Freundlich model, presenting heterogeneous adsorption sites on the surface of chitin. This is probably because multiple interactions are present in this system where dye could interact with different sites of the adsorbent. Our results also show that the $1 / n$ value (0.4195) for AY25 dye adsorption is between 1 and 0 ,

Table 3. Isotherm parameters obtained from different models with an initial dye concentration of $385 \mathrm{mg} / \mathrm{mL}$ and chitin dosages of $1,2,3,4$, and $5 \mathrm{~g} / \mathrm{L}$ at $23^{\circ} \mathrm{C}$ and $\mathrm{pH}=2$.

\begin{tabular}{ccccc}
\hline Isotherm Model & \multicolumn{4}{c}{ Parameters } \\
\hline Langmuir & $q_{\max }(\mathrm{mg} / \mathrm{g})$ & $b(\mathrm{~L} / \mathrm{mg})$ & $R_{L}$ & $R^{2}$ \\
\hline \multirow{3}{*}{ Freundlich } & 303 & 0.045 & 0.055 & 0.9951 \\
& $K_{F}(\mathrm{~L} / \mathrm{g})$ & $1 / n$ & & $R^{2}$ \\
& 37.35 & 0.4195 & & 0.9884 \\
D-R & $q_{D}(\mathrm{~mol} / \mathrm{g})$ & $\beta_{D}\left(\mathrm{~mol}^{2} / J^{2}\right)$ & $E_{D R}(\mathrm{~kJ} / \mathrm{mol})$ & $R^{2}$ \\
& 0.00202 & $3.36 \times 10^{-9}$ & 12.20 & 0.9934 \\
Temkin & $A_{T}(\mathrm{~L} / \mathrm{mg})$ & $\left.B\left(\mathrm{~mol}^{2} / \mathrm{k}\right)^{2}\right)$ & $b_{T}(\mathrm{~J} / \mathrm{mol})$ & $R^{2}$ \\
& 0.888 & 46.14 & 53.34 & 0.9467 \\
\hline
\end{tabular}


and thus the adsorption process is favorable under the studied conditions.

We then used the Dubinin-Radushkevich (D-R) isotherm model to test the nature of the chemical and physical means of adsorption [18]. The D-R isotherm equations are shown below [19]:

$$
\begin{aligned}
& q_{e}=q_{D} \exp \left(-\beta_{D} \varepsilon^{2}\right) \\
& \ln q_{e}=\ln q_{D}-\beta_{D} \varepsilon^{2}
\end{aligned}
$$

where $q_{D}$ is Dubinin-Radushkevich monolayer saturation capacity (mol/g); $\beta_{D}$ is the constant related to the mean free energy of adsorption per mole of the adsorbate $\left(\mathrm{mol}^{2} / \mathrm{J}^{2}\right)$; and $\varepsilon$ is the Polyani potential $(\mathrm{J} / \mathrm{mol})$ and defined as $\left.\varepsilon=R T \ln \left(1+1 / C_{e q}\right)\right)$ ( $R$ is the gas constant and $T$ is absolute temperature). By plotting $\ln q_{e}$ versus $\mathcal{E}^{2}, q_{D}$ and $\beta_{D}$ can be obtained. The constant $\beta_{D}$ gives an idea about the mean free energy, where the mean free energy can be calculated using $E_{D R}=\frac{1}{\sqrt{2 \beta_{D}}}$. All initial dye concentrations of AY25 dye tested show a good agreement to the D-R isotherm model. The correlation for this isotherm is higher when compared to the Freundlich isotherm. The fitted results indicate the $E_{D R}$ value is $12.20 \mathrm{~kJ} / \mathrm{mol}$ (Table 3), which is between 8 and $16 \mathrm{~kJ} / \mathrm{mol}$ for chemisorption via ion-exchange [20]. The chemisorption appears to attribute from the electrostatic attraction between positively charged chitin [1] and negatively charged dye at $\mathrm{pH} 2$ as described previously.

The Temkin adsorption isotherm is used to determine the interaction between adsorbate and adsorbent [21]. The model assumes that heat of adsorption of all molecules in the layer decreases linearly with surface coverage due to adsorbent-adsorbate interactions. Adsorption is thus characterized by a uniform distribution of binding energies. The Temkin adsorption isotherm is given in Equation 14 [22].

$$
\begin{gathered}
q_{e}=\frac{R T}{b_{T}} \ln \left(A_{T} C_{e}\right) \\
q_{e}=B \ln A_{T}+B \ln C_{e}
\end{gathered}
$$

where $A_{T}$ is the Temkin isotherm equilibrium binding constant (L/mg); $b_{T}$ is the Temkin isotherm constant related to the heat of adsorption $(\mathrm{J} / \mathrm{mol})$, and $B=$ $R T / b_{T}\left(R\right.$ is $8.314 \mathrm{~J} \mathrm{~mol}^{-1} \mathrm{~K}^{-1}$ and $T$ is absolute temperature in Kelvin). A plot of $q_{e}$ versus $\ln C_{e}$ enables the determination of the isotherm constants $B$ and $A_{T}$ from the slope and the intercept, respectively. The calculated coefficient of determination $\left(R^{2}\right)$ shows that the experimental data does not have a very good fit $\left(R^{2}=0.9471\right)$ with the Temkin isotherm (Table 3 ), indicating that the binding energy is not uniformly distributed up to its maximal binding energy.

\section{Conclusions}

Here we have shown that the AY25 adsorption onto chitin (particle size of 297 to $177 \mu \mathrm{m})$ at $\mathrm{pH} 2$ and room temperature with a shaking rate of $70 \mathrm{rpm}$ can be 
described best by a pseudo-second order model. The intraparticle study indicates that the adsorption is mainly controlled by a film adsorption process. By varying the amounts of AY25 and chitin, we have determined that the rates of pseudo-second order adsorption and boundary layer diffusion that are a complex function of both initial concenentration of AY25 $\left(C_{o}\right)$ and the dosage of chitin (D) as defined in Equations (7) and (10).

The adsorption isotherms of AY25 onto chitin were also analyzed using different models, including the Langmuir, Freundlich, D-R, and Temkin isotherms. Our adsorption data showed a good correlation for all isothermal models except for the Temkin model. Among them, the Langmuir isotherm showed the highest correlation, suggesting that the surface of chitin contains a monolayer with heterogeneous adsorption sites. Additionally, the separation factor $\left(R_{L}\right)$ from the Freundlich isotherm indicated that such an adsorption is favorable. The mean free energy of adsorption in D-R was $12.2 \mathrm{~kJ} / \mathrm{mol}$, which accounts for the adsorption of AY25 dye onto chitin being chemisorption, primarily through ion-exchange interactions. The maximum AY25 adsorption capacities of chitin $\left(q_{\max }\right)$ obtained from the Langmuir and Freundlich isotherm models were $\sim 300$ and $320 \mathrm{mg} / \mathrm{g}$, which are comparable to those of chitin with other acidic dyes, such as Acid Blue 25 and 158 [23].

In summary, our study demonstrates that chitin can be effectively used for the removal of AY25 dye as shown by its high adsorption capacity and rapid adsorption via chemisorption and film mass transfer processes. Our study on the effects of $\mathrm{pH}$ and temperature also indicates that wide ranges of $\mathrm{pH}(2-7)$ and temperature $\left(20^{\circ} \mathrm{C}-70^{\circ} \mathrm{C}\right)$ are adequate for removal of the majority of the dye from solution, making chitin as an ideal adsorbent for AY25 in textile water.

\section{Acknowledgements}

We thank Marie Gipson for assisting with the preparation of chitin. We thank the internal financial support from Southern Illinois University Edwardsville: Seed Grants for Transitional and Exploratory Projects (STEP) to CW and the Undergraduate Research and Creative Activities (URCA) Associate and Assistant Awards to EF, KS, and NS. This work was supported in part by the National Science Foundation grant NSF-CHE \#1608484 to CW.

\section{References}

[1] Dotto, G.L., Vieira, M.L.G., and Pinto, L.A.A. (2012) Kinetics and Mechanism of Tartrazine Adsorption onto Chitin and Chitosan. Industrial \& Engineering Chemistry Research, 51, 6862-6868. https://doi.org/10.1021/ie2030757

[2] Thorat, P.R. and Shertate, S.R. (2013) Biotransformation of a Textile AZO Dye Acid Yellow 25 by Marinobacter Gudaonensis AY-13. Journal of Engineering, Computers, \& Applied Sciences, 2, 11

[3] Saibaba, N.K.V., King, P., Gopinadh, R. and Sreelakshmi, V. (2011) Response Surface Optimization of Dye Removal by Using Waste Prawn Shells. International Journal of Chemical Sciences and Applications, 2, 186-193. 
[4] Kumar, R. and Ahmad, R. (2011) Biosorption of Hazardous Crystal Violet Dye from Aqueous Solution onto Treated Ginger Waste (TGW). Desalination, 265, 112-118. https://doi.org/10.1016/j.desal.2010.07.040

[5] Blackburn, R.S. (2004) Natural Polysaccharides and Their Interactions with Dye Molecules: Applications in Effluent Treatment. Environmental Science \& Technology, 38, 4905-4909. https://doi.org/10.1021/es049972n

[6] Thirumalisamy, S. and Subbian, M. (2010) Removal of Methylene Blue from Aqueous solution by Activated Carbon Prepared from the Peel of Cucumis Sativa Fruit by Adsorption. Biosource Technology, 5, 419-437.

[7] Begum, H.A., Mondal, A.K. and Muslim, T. (2012) Adsorptive Removal of Reactive Black 5 from Aqueous Solution Using Chitin Prepared from Shrimp Shells. Bangladesh Pharmaceutical Journal, 15, 145-152. https://doi.org/10.3329/bpj.v15i2.12580

[8] DFO, S.C. (2018) U.S. National Marine Fisheries Service, Bank of Canada. http://www.dfo-mpo.gc.ca/fm-gp/peches-fisheries/reports-rapports/sc-cn_e.pdf

[9] Kasaai, M.R. (2009) Various Methods for Determination of the Degree of N-Acetylation of Chitin and Chitosan: A Review. Journal of Agricultural and Food Chemistry, 57, 1667-1676. https://doi.org/10.1021/jf803001m

[10] Sagheer, F.A.A., Al-Sughayer, M.A., Muslim, S. and Elsabee, M.Z. (2009) Extraction and Characterization of Chitin and Chitosan from Marine Sources in Arabian Gulf. Carbohydrate Polymers, 77, 410-419. https://doi.org/10.1016/j.carbpol.2009.01.032

[11] Stefancich, S., Delben, F. and Muzzarelli, R.A.A. (1994) Interaction of Soluble Chitosans with Dyes in Water. I. Optical Evidence. Carbohydrate Polymers, 24, 17-23. https://doi.org/10.1016/0144-8617(94)90112-0

[12] Iqbal, J., Wattoo, F.H., Wattoo, M.H.S., Malik, R., Tirmizi, S.A., Imran, M. and Ghangro, A.B. (2011) Adsorption of Acid Yellow Dye on Flakes of Chitosan Prepared from Fishery Wastes. Arabian Journal of Chemistry, 4, 389-395. https://doi.org/10.1016/j.arabjc.2010.07.007

[13] Saha, T.K., Bhoumik, N.C., Subarna, K.G., Ahmed, M.G., Hideki, I. and Yoshinobu, F. (2011) Adsorption Characteristics of Reactive Black 5 from Aqueous Solution onto Chitosan. CLEAN-Soil, Air, Water, 39, 984-993. https://doi.org/10.1002/clen.201000315

[14] Azizian, S. (2004) Kinetic Models of Sorption: A Theoretical Analysis. Journal of Colloid and Interface Science, 276, 47-52. https://doi.org/10.1016/j.jcis.2004.03.048

[15] Cheung, W.H., Szeto, Y.S. and McKay, G. (2007) Intraparticle Diffusion Processes during Acid Dye Adsorption onto Chitosan. Bioresource Technology, 98, 2897-2904. https://doi.org/10.1016/j.biortech.2006.09.045

[16] Gerente, C., Lee, V.K.C., Cloirec, P.L. and McKay, G. (2007) Application of Chitosan for the Removal of Metals from Wastewaters by Adsorption-Mechanisms and Models Review. Critical Reviews in Environmental Science and Technology, 37, 41-127. https://doi.org/10.1080/10643380600729089

[17] Mahmoodi, N.M., Hayati, B. and Arami, M. (2010) Textile Dye Removal from Single and Ternary Systems Using Date Stones: Kinetic, Isotherm, and Thermodynamic Studies. Journal of Chemical \& Engineering Data, 55, 4638-4649. https://doi.org/10.1021/je1002384

[18] Ling, S.L.Y., Yee, C.Y. and Eng, H.S. (2011) Removal of a Cationic Dye Using Deacetylated Chitin (Chitosan). Journal of Applied Sciences, 11, 1445-1448. https://doi.org/10.3923/jas.2011.1445.1448

[19] Do, D.D. (1998) Adsorption Analysis: Equilibria and Kinetics. Imperial College 
Press, London.

[20] Sari, A., Mendil, D., Tuzen, M. and Soylak, M. (2008) Biosorption of Cd(II) and $\mathrm{Cr}$ (III) from Aqueous Solution by Moss (Hylocomium splendens) Biomass: Equilibrium, Kinetic and Thermodynamic Studies. Chemical Engineering Journal, 144, 1-9. https://doi.org/10.1016/j.cej.2007.12.020

[21] Aharoni, C. and Ungarish, M. (1977) Kinetics of Activated Chemisorption. Part 2.-Theoretical Models. Journal of the Chemical Society, Faraday Transactions 1: Physical Chemistry in Condensed Phases, 73, 456-464. https://doi.org/10.1039/f19777300456

[22] Dada, A.O., Olalekan, A.P., Olatunya, A.M. and Dada, O. (2012) Langmuir, Freundlich, Temkin and Dubinin-Radushkevich Isotherms Studies of Equilibrium Sorption of $\mathrm{Zn}^{2+}$ onto Phosphoric Acid Modified Rice Husk. IOSR Journal of Applied Chemistry, 3, 38-45. https://doi.org/10.9790/5736-0313845

[23] Mc Kay, G., Blair, H.S. and Gardner, J. (1983) Rate Studies for the Adsorption of Dyestuffs onto Chitin. Journal of Colloid and Interface Science, 95, 108-119. https://doi.org/10.1016/0021-9797(83)90078-4 